\title{
Europe keeps space science budget level
}

[MUNICH] Europe's space ministers last week agreed on a level budget for joint space science activities over the next few years that will allow science missions already approved by the European Space Agency (ESA) - including a mission to Mars known as Mars Express - to be launched on schedule.

The ministers also approved the start of a new optional programme of scientific missions to observe the Earth, called the Living Planet. Nearly 600 million euros (US\$640 million) has been approved for its first four years of operation.

But the meeting was protracted and acrimonious. Although 13 of ESA's 14 member states were prepared to agree an annual one per cent increase in cash terms to the mandatory space science programme for the next five years, Germany held out for a decrease

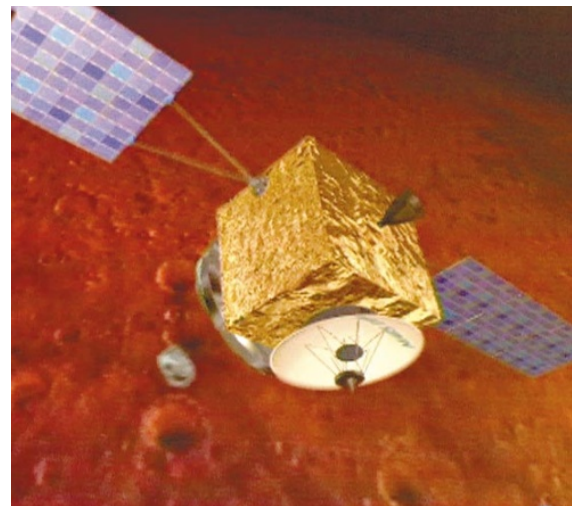

Full speed ahead: Mars Express is one of the missions to benefit from the budget agreement.

because it is already overcommitted in its own space budget (Nature 399, 4; 1999).

A hard-fought compromise limits the

\section{Britain finds money to renew infrastructure}

[LONDON] Christmas came early last week for 37 British research groups that are to share $\mathfrak{E} 150$ million (US $\$ 243$ million) in the first round of a scheme to renew research infrastructure. Funding comes from the government and the Wellcome Trust.

In total, $\mathfrak{E 7 0 0}$ million is to be spent on essential building, refurbishment and equipment projects under the Joint Infrastructure Fund (JIF). Researchers previously facing an uncertain future say they can now look forward to remaining internationally competitive. Against a backdrop of 20 years of underinvestment, a collective sigh of relief from the research community is almost palpable.

Individual awards are expected to range from one million to tens of millions of pounds (figures will be confirmed in the next few weeks). But most researchers admit to remaining nervous about the final sum they will receive. John Taylor, director-general of the UK Research Councils, says that the accounting for overheads and contingencies needs to be rigorously checked.

"We are clearly delighted," says Charles Godfray from Imperial College, London, a member of a team that put in a successful bid for $£ 2.4$ million towards new facilities for ecological research into climate change, biodiversity and microbial ecology. "This is absolutely tremendous. It is great seeing government invest in substantial infrastructure in universities."

At the University of Leeds, a project to develop, analyse and test transgenic crops will receive support. Three core programmes will look at transgenic transduction and control of gene expression, and whole-plant development.

A team from the University of Glasgow will receive funding to develop advanced detectors for the gravitational waves that are predicted to occur during violent astronomical events. Such detection will require highly sensitive equipment, and the team is working on advanced suspension systems for the mirrors within the detectors. Some $\mathfrak{E} 2.3$ million will be spent on an ultrahigh-vacuum room. Norna Robertson from the university says the money means they will remain internationally competitive.

At the University of Birmingham, a nanoscale science facility will receive support for what is claimed to be the world's first ultra-high-vacuum scanning transmission electron microscope. This will allow researchers to see below the surface of the three-dimensional nanometre-scale structures they build.

"We are learning how to fabricate on the nanometre scale," explains Richard Palmer of the university. The work will have an impact in areas such as materials science, chemistry, physics and electrical engineering.

The largest successful bid is thought to have come from a consortium of 18 UK

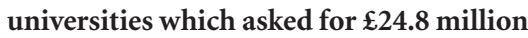
for the Visible and Infrared Survey Telescope for Astronomy (VISTA). This will survey large areas for very faint stars and galaxies. It is intended to be "a fundamental source of reference on the contents and layout of our own Galaxy". The group are apparently "thrilled". Natasha Loder resistance to nematode parasites, signal financial envelope to four, rather than five, years - from 1999 to 2002 — and divides it into two components. The first is a 'baseline budget', a flat continuation of the current 352 million euro annual budget, which is not linked to inflation. The second component, averaging 10 million euros per year, is called 'complementary science funding. Germany has committed itself to contributing only for the first year

The science budget will be topped up through internal reorganization of resources, adding a further 9 million euros over the four-year period. This means that, despite the uncertainty of the complementary funding, purchasing power is likely to be maintained at 1998 levels.

ESA's director of science, Roger Bonnet, says ESA will therefore be able to launch Mars Express, so called because of the speed of its design and launch, as planned in 2003, and the infrared cornerstone mission FIRST - together with the microwave background mission Planck - in 2007. Other scheduled missions, such as the X-ray astronomy cornerstone mission XMM (due for launch in December 1999), will also keep to target.

Bonnet is due to discuss the scheduling of future missions with ESA's Science Programme Committee in Bern this week. The committee will also plan the selection of two new missions, each costing around 175 million euros. One will be in astronomy - possibly a contribution to the Next Generation Space Telescope, an international project led by NASA - and one will be in a non-astronomy field such as fundamental physics.

Unlike the mandatory science programme, ESA member states can choose the level of their involvement in the Living Planet programme. The programme has already attracted sufficient support among ESA members states to proceed with its plans to launch a small or medium-size scientific mission every year beginning in 2002 (see Nature 399, 4; 1999). This time Germany, where earth observation is a major priority, is the largest contributor.

The United Kingdom pledged a total of more than $£ 100$ million (US\$160 million) to four new space programmes. In announcing a $£ 67$ million investment in the Living Planet project, Lord David Sainsbury, Britain's minister for science and space, said the agreement marked "the first step towards providing an assured long-term programme of scientific research which looks at the Earth and its environment from space".

Other programmes to receive UK contributions are the ARTES 3 satellite multimedia programme ( 227 million), the ARTES 1 satellite studies programme (£4.5 million) and the Galileosat navigation programme (also about $\mathfrak{E} 4.5$ million). $\quad$ Alison Abbott 